\title{
Nanotechnology and Environment Study
}

\author{
Nisreen Kadhim Jawad ${ }^{1}$ and Ebaa A. Hamooshy ${ }^{2}$ \\ ${ }^{1,2}$ College of Agriculture, University of Baghdad, Al-Jadriya, Baghdad, Iraq
}

\begin{abstract}
Nanotechnology has begun to be used to solve or at least mitigate environmental pollution problems, and in turn has provided a great opportunity to develop some strategies to protect the environment from pollution. Nanotechnology enables having the possibility to increase the efficiency of energy consumption, produce clean energy sources, solve the problem of water and air pollution and other environmental problems by developing new ways to provide and treat drinking water and discover air pollution. This stimulated the United Nations to pay attention to it and to monitor a plan to benefit from its applications in various fields. This paper reviews the impacts of nanotechnology on such environmental issues.
\end{abstract}

\section{Introduction}

The manufacture of microscopes and their development is taken into consideration in 1930. During the last few years, several potentials appeared that science could add to what is called Nanotechnology. This technology produced a huge item in all scientific and geometric fields, so engineers first were able to produce smaller devices, stronger and more efficient. The application of such devices was in electronic, computational and informative fields, as well as medical, agricultural, environmental and military fields $[1,2]$. The existence of nanocompositions dates back to the earth age and the beginning of life in the biological systems in human body which manufacture some small devices that is similar to the size of nano. These devices can interact inside the cell and perform different functions, like analysing the ingredients of the cell or delivering materials to it or ruin it when it becomes harmful [3].

Received: September 30, 2021; Revised: October 7, 2021; Accepted: October 9, 2021

Keywords and phrases: nanotechnology, environmental measurements.

Copyright (C) 2021 the authors. This is an open access article distributed under the Creative Commons Attribution License, which permits unrestricted use, distribution, and reproduction in any medium, provided the original work is properly cited. 


\subsection{The basics and characteristics of nanotechnology}

The idea of "technology" emerged from the Latin word "Nano", which means "dwarf". There are a lot of terms that is used in nanotechnology related to nanoscience, which is the science interested in studying the basic principles and the composition features of materials in measuring nano. Thus, the word "Nano" is utilised for the most accurate unit of length measurement, which is equal to $10^{-9} \mathrm{~nm}$.

All materials contain compact atoms in a certain arrangement, for example as a comparison between diamond and graphite, both are composed of carbon. In graphite, there is one carbon atom arranged in compact hexagonal shapes in parallel plates, while in diamond, the carbon atoms are arranged in octahedral crystal shape. Each one has its own features and use $[1,4,5]$.

The nanoparticles are defined as atomic or partial aggregation amounts to million atoms connected to each other in a spherical shape, its radius is less than (100 Nano). The nanoparticle that its radius is $(1 \mathrm{~nm})$ contains almost (25) atoms most of them are found on the surface of the particle [1,6,7]. The term "Nanocompositions" are used to express the result of adding nanoparticles to ordinary materials to create new materials ionized to make a great improvement in the quality of those materials, for example, carbon nanotubes that have a feature called "Electron Tunnelling". Adding carbon nanotubes lead to changing the connective, electrical, and thermic properties of nanocompositions, where they are characterised to be non-corrosive and incombustible in ordinary circumstances, as well as the ability of adding them to plastic to make it a conductor $[1,8,9]$.

Carbon nanotubes have been used as miniature wires to connect the separate components in computers. These tubes are characterized by extreme strength and durability, so adding them in small percentages to significantly improve the properties of fibres and other materials, and there are other applications [10].

\subsection{Nanotechnology and environment study}

Nanoparticles have begun to find their way into the environment around us as a result of the unlimited use of the nanotechnology products and nanomaterials, and that is why the sources of nanoparticles, their behaviour, and effects on the environment have been mentioned, as well as various technologies for assessing the spread, fate and behaviour of nanomaterials, in diverse environments in addition to the potential risks for particles and nanoparticles. 


\section{Analysis of Nanomaterials in Environmental Measurements}

The changes in the properties resulting from the changes in the measurement of particles are called (Size Effect) and the reason is due to the change in the bonding of the atoms and molecules that make up those particles. Also, the atoms and molecules on the surface are very active which facilitate the association with other materials, and changes happen in the physical properties such as the degree of their text, qualitative properties such as a dielectric constant, changes in reactivity (activation energy), solubility and all properties related to mass, heat transfer, change in reaction rate and others [9].

The study of the behaviour of nanoparticles and their harmful impact on the environment via analysing nanoparticles in various media after determining the composition and concentration. The use of nanoparticles separation technology is linked to an automated measurement technique to obtain a quantitative analysis, with high sensitivity [11]. The most important analyses and techniques used to identify materials and particles in diverse environments are:

\subsection{Qualitative analysis for nanoparticles}

a. Using optical spectroscopy technology: Several optical techniques have been used in the qualitative analysis of particles and nanomaterials, the most important of which is Raman spectroscopy which is regarded an appropriate technique to determine the structural properties of nanoparticles and X-ray spectroscopy, that gives information about the crystal structure of the surface layers and coated layers of nanoparticles, and surface nuclear magnatic field (NMR) spectroscopy was utilised to determine the threedimensional structure of the samples. Several optical techniques were combined and linked together, to identify carbon nanotubes in surface waters [26].

b. Several microscopes have been used to identify nanoparticles as well as moving and imaging them, and others, like: optical electron microscopes, including the scanning tunnelling microscope, the atomic force microscope, and the screening electron microscope [1,2].

\subsection{Quantitative analysis for nanoparticles}

Spreading nanoparticles in the environment is affected by different factors, such as oxidants, light and microbes. These effects cause chemical and physical transformations and dissolutions on the surface of functional groups that are associated with 
nanoparticles. The introduction of materials from the medium that are linked to the functional groups during these chemical transformations may cause the release of nanoparticles into the surrounding environment [12].

Some obstacles and challenges that may face quantitative analysis for nanoparticles are the process of taking samples and preparing them for analysis because they cause a change in the diffusion state of nanoparticles. The use of materials that helps spreading (surfactants) or the use of centrifuge to separate the nano-clusters. Using a device emitting vibrations helps to release the required nanoparticles. To add the ways of hydrodynamic chromatography and the separation of flow field and capillary electrophoresis in gel filtration which separate particles measuring from $100 \mathrm{~nm}$, which have been linked with a number of measurement techniques to soften nanoparticles. The most important standard techniques used are the mass scale, light scattering meter, the voltmeter, and the multi-angle laser photometer, by which it is possible to measure the properties of gold nanoparticles [13] and single-walled carbon tubes [14].

The presence of natural nanoparticles and organic materials in the sample leads to the difficulty of conducting the quantitative analysis, as well as the possibility of absorbing organic and inorganic nanoparticles on the wall of the sample vessels. The analysis of nanoparticles in the soil is a difficult process due to the presence of large quantities of natural particles of similar size to the nanoparticles that is to be analyzed. Nanoparticles containing a high percentage of transition metals with active surfaces can bind to others and thus, change their ability to harm or damage living cells [15].

\section{Sources of nanoparticles in the environment}

\subsection{The atmosphere}

Nanoparticles are important media to transfer different molecules from gaseous phase to the formation of aerosols (air barrier), which later turns into suspended droplets in the air [16]. The natural sources of nanoparticles in the atmosphere include volcanic eruptions, physical and chemical erosion of rocks, aeration of hydrothermal systems, forest fires and others. Nuclear radiation can be a medium for the spreading of inorganic nanoparticles into the atmosphere [17].

\subsection{Soil}

The typical example of nanomaterials found in soil is hydrated iron (Ferringdract) 
which is found everywhere in the soil [18]. Most of nanoparticles found in the soil are represented by the nano-metallic materials (such as manganese, iron and their oxides and hydroxides), in addition to natural organic materials and microbial clusters [19].

\subsection{The aquatic environment}

The small size of nanoparticles and their wide surface area make them significant in linking the organic and inorganic phases of pollutants where nanoparticles diffuse in the aquatic environment naturally in the form of several colloidal sites (such as clusters of metal sulfides resulting from hydrothermal systems and manganese oxides and hydrated iron). A study conducted in Germany and Sweden showed the ability of lead nanoparticles in water or soil to bind the colloidal iron oxides, which works to transfer and diffuse them with high efficiency. Studies are being conducted to find out the influence caused by some factors such as $\mathrm{pH}$ and ionic strength on clusters in nano-scale measurements [20]. Also, numerical studies are currently conducted to understand the physicochemical properties and their influence on their movement and toxicity in the healthy aquatic environment. The researches indicated the capacity of free nanoparticles to aggregate and absorb, which makes their movement and diffusion slow. The bonding and stability of nanoparticles (organic and inorganic) with organic materials, including pollutants, has a strong relation to its toxic impact in the aquatic environment. The possibility of nanoparticles accumulating with it to escape from filter holes or leaking factors [22,23].

The essential sources of the diffused nanoparticles in the environment can be listed in the following table $[25,26]$ :

Table 1: The essential sources of nanoparticles.

\begin{tabular}{|l|l|l|l|}
\hline Source & $\begin{array}{l}\text { Source of natural } \\
\text { origin }\end{array}$ & $\begin{array}{l}\text { Source of artificial } \\
\text { origin }\end{array}$ & $\begin{array}{l}\text { Engineered- } \\
\text { designed } \\
\text { nanoparticles }\end{array}$ \\
\hline Air & Volcanic eruption & Burning processes & $\begin{array}{l}\text { Following } \\
\text { nanotechnology } \\
\text { process }\end{array}$ \\
\hline & $\begin{array}{l}\text { Hot water nozzle } \\
\text { system }\end{array}$ & Industrial emissions & \\
\hline
\end{tabular}




\begin{tabular}{|c|c|c|c|}
\hline & Vital processes & & \\
\hline & $\begin{array}{l}\text { The disintegration } \\
\text { and dissolution } \\
\text { resulting from an } \\
\text { effect of the } \\
\text { strategy on aquatic } \\
\text { systems. }\end{array}$ & & \\
\hline & Nuclear processes & & \\
\hline \multirow[t]{3}{*}{ Soil } & $\begin{array}{l}\text { The nanominerals, } \\
\text { (e.g.: iron hydrate) }\end{array}$ & $\begin{array}{l}\text { Atmospheric } \\
\text { deposition }\end{array}$ & $\begin{array}{l}\text { Diffusion of } \\
\text { scattering } \\
\text { nanoparticles during } \\
\text { manufacturing and } \\
\text { use }\end{array}$ \\
\hline & $\begin{array}{l}\text { Accumulation of } \\
\text { natural organic } \\
\text { materials }\end{array}$ & $\begin{array}{l}\text { Absorption and } \\
\text { transmission of } \\
\text { aquatic systems }\end{array}$ & \\
\hline & $\begin{array}{l}\text { Vital sources (e.g. } \\
\text { urinate) }\end{array}$ & & \\
\hline \multirow[t]{3}{*}{ Water } & $\begin{array}{l}\text { Metal sulphide } \\
\text { nanoparticles }\end{array}$ & $\begin{array}{l}\text { Atmospheric } \\
\text { deposition }\end{array}$ & $\begin{array}{l}\text { Diffusion of } \\
\text { scattering } \\
\text { nanoparticles during } \\
\text { manufacturing and } \\
\text { use }\end{array}$ \\
\hline & hydrated Iron & & \\
\hline & Manganese oxide & & \\
\hline
\end{tabular}

In the table above, the main sources of diffused materials in the environment have been listed besides the behaviour of nanoparticles in the environment. It shows the diffusion of nanoparticles in the air, soil, and water environment in a natural or unnatural sources that contain waste processes and burning processes, in addition to diverse processes for the production of nanoparticles $[25,26]$. 


\section{Applications of Nanotechnology in the Environment}

Nanotechnology has been used to solve or at least reduce environmental, in which it provides new technical ways to solve environmental problems and as new methods have provided to treat drinking water. The progress happened in this technology motivates United Nations (UN) to pay attention to it and put a plan to benefit from its applications in different fields, as it provided great opportunities to develop some strategies to protect the environment from pollution and produce clean energy sources and increase their efficiency. It can also increase the industrial production enormously with low costs in medical, agriculture, food, space, military, and the environment [27,28]. These fields contributed to this technology, methods and nanotechnology [29,1]

\subsection{Air pollution detection}

Nanotechnology has provided particles with a very high sensitivity called (nano stereos). The idea depends on making nanoparticles to use palladium nanoparticles, zinc oxide nanowires, or carbon nanotubes, which causes a change in the electrical resistance and capacitance of these particles as a result of a change in electrical properties when they absorb gas particles pollutant. The pollution of air with toxic gases and elements that are invisible and imperceptible is one of the most dangerous kinds of pollution, and these particles can detect any pollution in the air meticulously that reaches the point of detecting a few particles of polluting vapours or gases [29,30].

\subsection{Water processing techniques}

The traditional treatment methods of drinking water and techniques that contain chemical processing, UV processing, and water desalination have been developed besides other ways by using nanotechnology, which helped raising the efficiency of those techniques and providing safe drinking water by reducing pollution. Nanotechnology was used to treat drinking water, sewage, and groundwater, which can be achieved in three mechanisms as the following [29]:

a. Electrochemical oxidation: This mechanism is specific to the material that is to be oxidized. The oxidation process extends on the surface of the carbon nanotubes at a certain voltage [1].

b. Nano-filtration: Nano aluminium silicate filters were employed to remove impurities and microbes from water without the need to use filters for dirt or chemical 
disinfectants. Nanotechnology helped generating very small holes reaching $(1 \mathrm{~nm})$, which can block organic materials (e.g. pesticide particles) and allow only water particles to pass through them. Filtration process can be carried out via using several membranes arranged in layers, where each layer works to achieve a certain kind of pollutant material found in the water. Work is currently in progress on marketing nanofiltres that give rapid water technique whereby a person can drink pure filtered water directly in varied sources such as groundwater or stagnant water, and thus, a membrane is created from the ferrous oxide known as (Ferroxane), which is employed to remove pollutants and organic waste. Also, carbon nanotubes and nanopores of aluminium oxide that can change its thickness, pore size, and permeability have been generated to block and prevent plankton, harmful substances, parasites and viruses to pass in fresh water sources such as lakes and rivers [30].

\subsection{Photocatalysis (Photo-analysis)}

The photocatalysis way contains using photoactive material, like titanium dioxide nanoparticles $\left(\mathrm{TiO}_{2}\right)$ which is a pellucid substance that shows superior effectiveness in eliminating chlorine-resistant bacteria (Clostridium perfringens) and depends on using laboratory nanomaterials for water processing more than using catalysts because nanomaterials are characterised to have surface pores to mix with the reactants. These reactions are activated by sunlight to damage colorants and sensory objects. The photocatalytic way is used from the existence of nanoparticles of titanium dioxide $\left(\mathrm{TiO}_{2}\right)$ to purify the air. Buildings have been coated with a layer of pellucid titanium dioxide, which absorb sunlight and interact with nitrogen oxides which pollutes air, creating nitric acid, which is washed with rain water. The photocatalytic process is an economical process, which does not generate by-products, where any person can put impure water in bottles and water can be purified as soon as exposed to the sun $[29,2]$.

In spite of the positive aspects that nanotechnology may bear in terms of development and facilitating life, it is given to the broad progresses of the technology, in which machines and devices of this technology replace human being at work as they work faster and with extreme accuracy.

But also it must be mentioned that nanoparticles are very small that it can penetrate the immune system in human body and can pass through the membranes of skin and lungs' cells. And what causes more worry is the ability of these particles to cross the blood-brain barrier. And what it leaves with pathological effects. The results of the study 
that are conducted clarify that the natural defence mechanisms of the human body treat nanoparticles like microorganisms. These particles can join each other to form largebodied fibres that white blood cells (Macrophages) cannot swallow. In addition, nanoparticles containing a high percentage of transition metals with active surfaces can connect with other particles. Thus, its ability to harm or destroy cells changes [I5].

\section{Conclusions}

Nanotechnology is defined as the science that studies the possibility of changing material at the nano level to produce new materials, and nano is a very small unit of measurement, one in a million in millimetres. This technology enters so many fields for the benefit of human being. But there are some difficulties in this technology such as the small size of particles of material, cannot be controlled, and the difficulty of controlling the particles of material after removing them from their place in order to direct them to other places, and the inability to predict the results of altering the particles, which means their harmful and direct effect on the environment.

Protection from these potential risks of nanotechnology requires distinguishing the properties of all nanoparticles and compositions and knowing their effects on cells and organs of the human body. The available methods are not symmetrical with the severity of the dangers associated with nanoparticles, and the devices for detecting and measuring nanoparticles in air, soil and water are still deficient. The available ways are not in line with the severity of the dangers associated with nanoparticles, especially those used in the study of toxicities in the environment.

\section{References}

[1] Noha Al-Habashi, What is nanotechnology - a brief introduction in the form of simplified lessons, first edition, King Fahd National Library, Riyadh, Saudi Arabia, 2009

[2] A. Keiper, The Nanotechnology Revolution, The New Atlantis (A Journal of Technology \& Society), 2003.

https://www.thenewatlantis.com/wp-content/uploads/legacy-pdfs/TNA02-Keiper.pdf

[3] Muhammad Al-Salihi and Abdullah Al-Dowayan, Introduction to nanotechnology, Publication on the occasion of the Nano Research Workshop in Universities, Department of Physics and Astronomy, College of Science, King Saud University, Riyadh, Saudi Arabia, 2007. 
[4] B.C. Yadav and R. Kumar, Structure, properties and applications of fullerenes, International Journal of Nanotechnology and Applications 2 (2008), 15-24.

[5] M.L. Cohen, Nanotubes, nanoscience and nanotechnology, Materials Science and Engineering C 15 (2001), 1-11. https://doi.org/10.1016/S0928-4931(01)00221-1

[6] R.B. Gupta and U.B. Kompella, Fundamentals of drug nanoparticles, in: Nanoparticles Technology for Drug Delivery, Vol. 159, Taylor \& Francis Group, New York, USA, 2006, pp. 1-19.

[7] S.K. Sahoo, S. Parveen and J.J. Panda, The present and future of nanotechnology in human health care, Nanomedicine 3 (2007), 20-31.

https://doi.org/10.1016/j.nano.2006.11.008

[8] M.E. Ibrahim, Micro- and nano-biotechnology for applied pharmacognosy, $\mathrm{PhD}$ thesis, Nagoya-University, Tokyo, Japan, 2009, pp. 35-38.

[9] M. Hosokawa, K. Nogi, M. Naito and T. Yokoym, Basic properties and measuring methods of nanoparticles, in: Nanoparticles Technology Handbook, 1st ed., Elsevier Linacre House, Oxford, UK, 2007, 511 pp.

[10] P. Diwan and A. Bhardwaj, The Nanoscope Encyclopaedia of Nanoscience and Nanotechnology, Pentagon Press, USA, 2005.

[11] K. Tiede, A.B. Boxall, S.P. Tear, J. Lewis, H. David and M. Hassellov, Detection and characterization of engineered nanoparticles in food and the environment, Food Additives and Contaminants 25 (2008), 795-821. https://doi.org/10.1080/02652030802007553

[12] A.J. Kennedy, M.S. Hull, J.A. Steevens, K.M. Dontsova, M.A. Chappell, J.C. Gunter and C.A. Weiss, Factors influencing the partitioning and toxicity of nanotubes in the aquatic environment, Environmental Toxicology and Chemistry 27 (2008), 1932-1941. https://doi.org/10.1897/07-624.1

[13] J.T. Au, G. Craig, V. Longo, P. Zanzonico. M. Mason, Y. Fong and P.J. Alien, Gold nanoparticles provide bright long-lasting vascular contrast for CT imaging, American Journal of Roentgenology 200 (2013), 1347-1351. https://doi.org/10.2214/AJR.12.8933

[14] K.J. Ziegler, D.J. Schmidt, U. Rauwald, K.N. Shah, E.L. Flor, R.H. Hauge and R.E. Smalley, Length-dependent extraction of single-walled carbon nanotubes, Nano Letters 5 (2005), 2355-2359. https://doi.org/10.1021/n10510208

[15] R.D. Handy and B.J. Shaw, Toxic effects of nanoparticles and nanomaterials: implications for public health, risk assessment and the public perception of nanotechnology, Health, Risk \& Society 9 (2007), 125-144.

https://doi.org/10.1080/13698570701306807 
[16] D.D. Lucas and H. Akimoto, Contributions of anthropogenic and natural sources of sulfur to $\mathrm{SO}_{2}, \mathrm{H}_{2} \mathrm{SO}_{4}(\mathrm{~g})$ and nanoparticle formation, Atmospheric Chemistry and Physics Discussions 7 (2007), 7679-7721. https://doi.org/10.5194/acpd-7-7679-2007

[17] D. Rejeski and D. Lekas, Nanotechnology field observations: scouting the new industrial west, Journal of Cleaner Production 16 (2008), 1014-1017. https://doi.org/10.1016/j.jclepro.2007.04.014

[18] R.D. Handy, R. Owen and E. Valsami-Jones, The ecotoxicology of nanoparticles and nanomaterials: current status, knowledge gaps, challenges and future need, Ecotoxicology 17 (2008), 315-325. https://doi.org/10.1007/s10646-008-0206-0

[19] P.A. Maurice and M. F. Hochella, Nanoscale particles and processes: a new dimension in soil science, Advances in Agronomy 100 (2008), 123-153.

https://doi.org/10.1016/S0065-2113(08)00605-6

[20] R.F. Domingos, N. Tufenkji and K.J. Wilkinson, Aggregation of titanium dioxide nanoparticles: role of a fulvic acid, Environmental Science \& Technology 43 (2009), 1282-1286. https://doi.org/10.1021/es8023594

[21] Y.S. Hwang and Q. Li, Characterizing photochemical transformation of aqueous $\mathrm{nC}_{60}$ under environmentally relevant conditions, Environmental Science \& Technology 44 (2010) 3008-3013. https://doi.org/10.1021/es903713j

[22] K. Tiede, S.P. Tear, H. David and A.B.A. Boxall, Imaging of engineered nanoparticles and their aggregates under fully liquid conditions in environmental matrices, Water Research 43 (2009), 3335-3343. https://doi.org/10.1016/j.watres.2009.04.045

[23] C.E. Mackay, M. Johns, J.H. Salatas, B. Bessinger and M. Perri, Stochastic probability modeling to predict the environmental stability of nanoparticles in aqueous suspension, Integrated Environmental Assessment and Management 2 (2006), 293-298. https://doi.org/10.1002/ieam.5630020309

[24] R. Owen and R. Handy, Formulating the problems for environmental risk assessment of nanomaterials, Environmental Science Technology 41 (2007), 5582-5588. https://doi.org/10.1021/es072598h

[25] M. Farré, J. Sanchís and D. Barceló, Analysis and assessment of the occurrence, the fate and the behavior of nanomaterials in the environment, TrAC Trends in Analytical Chemistry 30 (2011), 517-527. https://doi.org/10.1016/j.trac.2010.11.014

[26] X. Qu, P.J.J. Alvarez and Q. Li, Applications of nanotechnology in water and wastewater treatment, Water Research 47 (2013), 3931-3946.

https://doi.org/10.1016/j.watres.2012.09.058 
[27] Dalia Mohamed Bassiouni, The nanotechnology revolution, 2014. http://kenanaonline.com/users/ahmedkordy/posts/320181

[28] F. Boehm, Nanotechnology in environmental applications, Report NANO39A, BCC Research, Norwalk, 2006. http://www.bccresearch.com/report/NANO39A.html

[29] R.K. Ibrahim, M. Hayyan, M.A. AlSaadi, A. Hayyan and S. Ibrahim, Environmental application of nanotechnology: air, soil, and water, Environmental Science and Pollution Research 23 (2016), 13754-13788. https://doi.org/10.1007/s11356-016-6457-z

[30] Hassan J. Al-Hail, Tag-Eldin O. Sokrab, Nasir J. Al-Moslamani and Francisco R. Miyares, Hypothalamic hamartoma presenting with gelastic seizures, generalized convulsions, and ictal psychosis, Neurosciences 15(1) (2010), 43-45. 